\title{
Net Economic Base Multipliers and Public Policy
}

\section{Charles L. Leven*}

\begin{abstract}
The regional multiplier ordinarily applied to regional impact simulations is the Keynesian foreign trade multiplier. This assumes that all of the increase in aggregate demand is from the region's "export" sector. In many applications, there can be offsetting changes in domestic demand with multipliers of their own. It is possible in many cases for the net multiplier to be less than 1.0. In extreme cases of differences in the import component of exports and displaced domestic demand, the net multiplier could be negative.
\end{abstract}

Regional analysts have long been familiar with the nonbasic-basic ratio seen as an estimator of the multiplier impact of exogenous changes in the basic sector. Most typically it posits that

$$
\mathrm{E}=\mathrm{E}_{\mathrm{nb}}+\mathrm{E}_{\mathrm{b}} \text {, }
$$$$
\text { where } E_{n b}=\left(\frac{E_{n b}}{E_{b}}\right)_{0} E_{b}
$$

so that

$$
E=\left[\frac{E_{n b}}{E_{b}}+1\right] E_{b}, \quad \text { or } \frac{d E}{d E_{b}}=\left[\frac{E_{n b}}{E_{b}}-1\right],
$$

where $\mathrm{E}_{,} \mathrm{E}_{\mathrm{nb}}$, and $\mathrm{E}_{\mathrm{b}}$ are total, nonbasic (or local), and basic (or export) employment, respectively. Note that it makes no essential difference if the analysis were carried out in terms of total output or income generated instead of employment; the multipliers would still have the same values relative to the underlying data. For any region, of course, $\mathrm{E}_{\mathrm{nb}} / \mathrm{E}_{\mathrm{b}}$ is simply the ratio of employment in producing goods in the region for sale within the region to employment in producing goods in the region for sale outside. $E_{n b} / E$ is nothing more than the employment corresponding to the average propensity to consume in the region minus the average propensity to import consumer goods.

For the U.S., if we observe long-run marginal (i.e., current average) propensities to consume, or $\mathrm{dC} / \mathrm{dY}$ of 0.90 to 0.95 , and propensities to import, or $\mathrm{dM} / \mathrm{dY}$ of 0.20 to 0.25 , then the Keynesian foreign trade multiplier of $1 / 1$ - (MPC - MPM) would have a value of somewhere between $31 / 3$ and 4 . At the same time, planning studies often indicate a nonbasic-basic ratio, $E_{n b} / E_{b}$, of 3, 4 , or even 5 . This would mean a regional foreign trade multiplier of $\left(1+E_{n b} / E_{b}\right)$, or 4,5 , or even 6 . But the foreign trade multiplier for a region nested within a nation would have to be smaller (equal to, in the limiting case) than the value for the larger nation. In general, $C / Y$ would be the same for region and nation, but $M / Y$ would be larger for the region since imports to the region would include 
imports from the nation outside the region as well as the region's pro rata share of imports from outside the nation.

This suggests some hidden logical flaw in the concept of the economic base multiplier, but this is not the case, since it is equal to

$$
\frac{E_{n b}}{E_{b}}+1=\frac{\left(E_{n b}+E_{b}\right)}{E_{b}}=\frac{E}{E_{b}}=\frac{E}{\left(E-E_{n b}\right)}=\frac{1}{\left[\frac{\left(E-E_{n b}\right)}{E}\right]}=\frac{1}{\left[1-\frac{E_{n b}}{E}\right]}
$$

But, since $E_{n b}=E_{C}-E_{M}$ and $E=E_{Y}$ where $E_{C}, E_{M}$, and $E_{Y}$ are proportional to $C, M$, and $Y$, then

$$
\frac{E_{n b}}{E_{b}}+1=\frac{1}{[1-(C / Y-M / Y)]^{\prime}}
$$

or the nonbasic-basic ratio multiplier is the Keynesian foreign trade multiplier at least where average propensities to consume and import are reasonable estimates of marginal propensities. But where growth is occurring via in-migration of labor (as opposed to increases in average return to labor), the marginal propensities in the long run will be the short-run average propensities.

Thus, what is wrong with nonbasic-basic multipliers is nothing conceptual, but rather observational. Specifically, where the empirical techniques used to estimate export percentages of individual sectors essentially measure net rather than gross multipliers, which commonly is the case in applications, then exports will be underestimated, which means the multiplier will be overestimated. But this is only one of the reasons for the overestimation of multipliers.

Borrowing from conventional macroeconomic analysis, it would appear that the range of estimates for the Keynesian foreign trade multiplier is from one to infinity-one where a shift in domestic demand is satisfied entirely by increasing imports. An example would be the case of a new household moving to the region that earned all of its income outside (say, from commuting) and spent none of its income inside the region. The increase in income, $Y$, would simply be equal to the income of the new family. A multiplier approaching infinity would result from a new household earning all its income outside the region and spending all of its income (saving nothing) in the region, or

$$
\frac{1}{[1-(\mathrm{C} / \mathrm{Y}-\mathrm{M} / \mathrm{Y})]}=\frac{1}{1}-(1-0)=\frac{1}{1}-1 \text {. }
$$

But this would be the case if the initial, exogenous shift in demand were entirely new demand, leaving other demands in the region unchanged.

In the extreme, consider for example an increase in the demand for meals at a new restaurant that resulted in an exactly equal and opposite decrease in demand for meals at other existing restaurants. Assuming identical direct and indirect import composition of the production functions for all restaurants, the multiplier here would be zero. So, multipliers would not range from one to infinity, 
but possibly from zero to infinity. In fact, under extreme conditions the multiplier could even be negative. For example, where the direct and indirect import components of producing meals at the "new" restaurant were greater than those of the "displaced" restaurant!

In fact, the ordinary Keynesian foreign trade multiplier is not the multiplier for the general case, but the multiplier for the Marshallian stationary state where the supply of inputs (in particular, labor) has either zero elasticity or, in the limiting case, might grow at a fixed and exogenous rate. By definition, all of the multiplier-indicated increase in output would be reflected in increases in average earnings of workers, with the number of workers remaining the same. This is simply the short-run aggregate multiplier under full employment. The analogous case for a regional economy would be an increase in employment where the elasticity of labor supply was infinite and all of the new demand was export demand. But, in fact, traditionally this is the case that regional planners ordinarily have in mind when they talk about the multiplier impact of a "new factory" selling all of its output outside the region, starting from initial full employment of the initial labor force.

Actually, depending on the initial conditions, multiplier impacts of a new enterprise in the region could range all the way from indefinitely large down to one, down to below one, to zero, and conceivably even negative. For example, a very high multiplier might result from a new federal installation with all of the workers transferred in from outside the region, especially if significant nonlabor inputs were acquired locally. The same facility might have a little lower multiplier in a smaller scale region as a higher percentage of consumer spending would be made up of imports. A very high multiplier might also result from a new industrial facility, again especially if much of its input requirements were met locally. An even higher multiplier on employment might be expected for business services serving an outside market.

Trade and recreation facilities would have a somewhat lower impact, as in most cases at least a part of their demand would result from displacement of demand by current residents at already existing facilities (either those competing directly by offering a similar or close substitute directly, or just competing for consumer dollars). These kinds of offsets might be expected for sports and recreation and entertainment facilities, including gaming facilities. Ordinary retail shopping facilities might be almost all offset by reductions in demand at other area facilities, except for very large or distinctive projects that could draw a great many of outof-town customers. On the other hand, sometimes the local existing demand that would be displaced might be a demand for imports. A new gaming casino, for example, might to a considerable extent be a substitute for trips to outside facilities that drew demand away from the area before the casino was built. Finally, something like a new small diner, fast food outlet, or barbershop might have a multiplier near zero as whatever success they would have would likely be at the expense of existing businesses. 
The important point for regional analysis is that different new additions to the local economy might have quite different multiplier impacts. In part this would depend on differences that are pretty well understood, like scale of the project and the region and the nature and amounts of local inputs used in production. But they might also depend very much on differences in displacement of existing demands and/or the extent to which new or increased taxes on local or nonlocal customers were a feature of new development, such as a tax on casino receipts, for example. In that case, to the extent it was on regional patrons, its effect would be to transfer income from households, whose marginal propensity to consume would be less than one, to state and/or local governments, whose marginal propensity to consume would be one. This difference would add some net multiplier effect. Additional multiplier effects could result if the inputs to households were more import intensive than the inputs to government; typically, this probably would be the case.

The point of this discussion is to highlight the fact that, for any region, the value of the multiplier for a new development within the region is not some fixed number depending on the economic characteristics of the region, but that it also would vary depending on characteristics of the development. In any debate over proposed new developments it is likely that proponents will try to represent the appropriate multiplier as being as high as possible, while opponents will try to estimate the multiplier as low as they can. The above discussion should make clear that there is more room for "manipulating" multiplier values than is normally supposed. Accordingly, policy analysts should be on warning that they must carefully determine the exact assumptions and calculations underlying the "multiplier" implications of proposals by varying parties to policy debate concerning development proposals. 